\title{
Atomoxetine Augmentation in a Case of Treatment Resistant Panic Disorder with Multiple Augments Failure: A Case Report
}

\author{
Dushad Ram¹, Shwetha Patil', Basavana Gowdappa², Iyshwarya Rajalakshmi ${ }^{1}$ \\ Departments of ${ }^{1}$ Psychiatry and ${ }^{2}$ Medicine, JSS Medical College, Mysore, India
}

\begin{abstract}
Atomoxetine, a selective norepinephrine inhibitor, is effective in comorbid anxiety and attention deficit hyperactivity disorder, however its role in panic disorder is unknown. We are presenting a case of panic disorder, who initially partially responded to clonazepam. When clonazepam was added with sertraline, escitalopram, desvenlafaxin, she did not improve significantly until paroxetine was added. When clonazepam-paroxetine combination was added with propranolol, etizolam, olanzepine, risperidone and amisulpride the symptom remission did not occur until a trial of Atomoxetine was done.
\end{abstract}

KEY WORDS: Atomoxetine augment; Treatment resistant panic disorder; Selective norepinephrine reuptake inhibitor.

\section{INTRODUCTION}

Lifetime prevalence of panic disorder is about $4 \%{ }^{1)}$ Ninety six percent of them seek treatment; $30 \%$ do not respond to $\geq 2$ serotonin-specific reuptake inhibitor and augmentation is needed. ${ }^{2,3)}$ Though the role of atomoxetine in primary anxiety disorder is not promising, ${ }^{4,5}$ it is effective in treating attention deficit hyperactivity disorder with comorbid anxiety disorder.

\section{CASE}

A 60 years old separated Muslim female of middle socioeconomic status was referred from department of emergency medicine. She had multiple unpredictable, spontaneous episodes that would start suddenly, severity reaching to its peak after about $15 \mathrm{~min}$ and characterized by apprehension, pounding heart, difficulty in breathing, nausea, abdominal distress, fear of dying, dizziness, tingling sensations and sweating. Each episode would last up to two hours, followed by generalized body ache and tiredness for days. Symptoms started 3 years back in frequency of four or more episodes per week. Except for the hospital

\footnotetext{
Received: February 23, 2015 / Revised: April 8, 2015

Accepted: May 13, 2015

Address for correspondence: Dushad Ram, MD

Department of Psychiatry, JSS Hospital, MG Road, Mysore, Karnataka, India 570004

Tel: +821-2-335-501, Fax: +821-2-335-187

E-mail: akashji1972@gmail.com
}

emergency room visits, she remained at home most of the time to avoid any episode away from home and to take a rest. She had stopped working, would remain preoccupied with future recurrence of episode and was sad due to these episodes. She did not report loss of interest, slowness in activities or worthlessness. Her sleep and appetite were reduced markedly. Mental status examination corroborated the history. She scored high on the Panic Disorder Severity Scale (PDSS=19, markedly ill). Physical examination and investigations (thyroid function test, fasting and post prandrial blood sugar, urine drug screening and electrocardiography) were within normal limit.

In the past, she had three episodes of severe major depression; received antidepressants (escitalopram $20 \mathrm{mg}$ ) and electroconvulsive therapy and maintained well after discontinuation of medication. There was no significant personal history or family history of mental illness.

A diagnosis of panic disorder with agoraphobia was made. Tablet clonazepam $0.5 \mathrm{mg}$ was started and optimized to $2 \mathrm{mg}$ in two divided doses. Due to daytime drowsiness, the dose could not be increased further. The severity of symptom improved mildly, but the frequency of episodes remained the same (PDSS=16). Tablet sertraline $25 \mathrm{mg}$ was added and increased by $25 \mathrm{mg}$ every two weeks till $75 \mathrm{mg}$, but no improvement observed. At 100 $\mathrm{mg}$ the patient developed severe nausea, giddiness and loss of appetite, hence it was stopped and tablet amitriptiline $12.5 \mathrm{mg}$ was started. The patient reported improvement in adverse effect, but all adverse effects reappeared

(a) This is an Open-Access article distributed under the terms of the Creative Commons Attribution Non-Commercial License (http://creativecommons.org/licenses/by-nc/4.0) which permits unrestricted non-commercial use, distribution, and reproduction in any medium, provided the original work is properly cited. 
when the dose hiked to $25 \mathrm{mg}$ after a week. Similarly a trial of escitalopram (started with $5 \mathrm{mg}$ for a week, then increased to $10 \mathrm{mg} /$ day) and desvenlafaxine sustained release (started with $25 \mathrm{mg} /$ day for a week, then increased to $50 \mathrm{mg} /$ day) was also given for three weeks each, but no improvement was observed. Later tablet paroxetine control release was added (started with $12.5 \mathrm{mg} /$ day and optimized to $25 \mathrm{mg} /$ day). The number of episodes reduced by 1-2 per week, but the severity of symptoms did not change over 4 weeks (PDSS=15). With this improvement she started doing household work occasionally. An attempt to increase by $12.5 \mathrm{mg}$ resulted in severe nausea and decreased appetite. Since clonazepam and paroxetine combination was helpful in symptom control, both were continued. A trial of adding tablet propranolol $40 \mathrm{mg} / \mathrm{day}$, etizolam $2 \mathrm{mg} /$ day, olanzepine $7.5 \mathrm{mg} /$ day, risperidone 2 $\mathrm{mg}$ /day and amisulpride $50 \mathrm{mg}$ /day for three weeks each did not bring further improvement. Finally, keeping in view of nor-adrenergic property tablet atomoxetine $5 \mathrm{mg}$ was added in the morning and afternoon. She reported significant improvement in severity of symptoms and frequency of episodes (PDSS=8). After 4 weeks, the dose was increased to $10 \mathrm{mg}$ and both symptoms and frequency improved markedly (PDSS $=5$ ). She resumed her routine and did not report any side effect. She was later given relaxation training and breathing exercise. On follow-up, she was maintaining well without any significant side effect.

In summary, initially patient partially responded to clonazepam. When clonazepam was added with sertraline, escitalopram, desvenlafaxine, she did not improve significantly until paroxetine was added. When clonazepam-paroxetine combination was added with propranolol, etizolam, olanzepine, risperidone, and amisulpride, the symptom remission did not occur until a trial of atomoxetine was done (Table 1).

\section{DISCUSSION}

In this case, atomoxetine augment was effective in controlling the severity and frequency of treatment resistant panic disorder. It selectively inhibits the presynaptic norepinephrine transporter resulting in inhibition of norepinephrine reuptake at locus coeruleus. ${ }^{6}$ In panic disorder, there is elevated peripheral sympathetic arousal, abnormal functioning of $\alpha$-adrenergic receptors, altered sensitivity of presynaptic and postsynaptic central $\alpha_{2}$-adrenergic receptors. ${ }^{7,8)}$ Locus coeruleus (nor-adrenergic nucleus) appears to play a major role through afferent input, in mediating visceral symptoms of severe anxiety. Report of Yohimbin induced panic attack and reduced locus coeruleus neuronal activity with medication used in the treatment of panic disorder, supports the role of the locus coeruleus. Animal studies have shown that atomoxetine can increase the extracellular levels of norepinephrine and dopamine up to 3-fold in the prefrontal cortex, without concurrent increases in serotonin, and also reduces stress related heart rate. ${ }^{9,10)}$ Paroxetine, a potent selective serotonin (5-hydroxytryptamine) reuptake inhibitor (SSRI), predominantly acts at raphe nuclei than locus coeruleus and helpful in controlling cognitive symptoms of anxiety. ${ }^{11)}$ Similarly, clonazepam has predominant GABA-ergic property and more effective in cognitive symptoms of anxiety than autonomic symptoms. In this case, the role of clonazepam and atomoxetine appeared to be crucial, as first would act in different parts of the brain and control the cognitive symptoms, while the second would selectively act at locus coeruleus and controls the visceral symptom

Table 1. Summary of medications

\begin{tabular}{clcclc}
\hline $\begin{array}{c}\text { Serial } \\
\text { number }\end{array}$ & Name of medication & $\begin{array}{c}\text { Starting dose } \\
(\mathrm{mg} / \text { day })\end{array}$ & $\begin{array}{c}\text { Maximum dose } \\
(\mathrm{mg} / \mathrm{day})\end{array}$ & Effect & Course of medication \\
\hline 1 & Clonazepam & 0.5 & 2.0 & Mild improvement & Continued \\
2 & Sertraline & 25.0 & 100.0 & No improvement & Discontinued due to side effect \\
3 & Amitriptiline & 12.5 & 25.0 & No improvement & Discontinued due to side effect \\
4 & Escitalopram & 5.0 & 10.0 & No improvement & Discontinued \\
5 & Desvenlafaxine & 25.0 & 50.0 & No improvement & Discontinued \\
6 & Paroxetine & 12.5 & 25.0 & Further mild improvement & Continued \\
7 & Propranolol & 20.0 & 40.0 & No improvement & Discontinued \\
8 & Etizolam & 0.5 & 2.0 & No improvement & Discontinued \\
9 & Olanzepine & 2.5 & 7.5 & No improvement & Discontinued \\
10 & Risperidone & 0.5 & 2.0 & No improvement & Discontinued \\
11 & Amisulpride & 50.0 & 50.0 & No improvement & Discontinued \\
\hline
\end{tabular}


of anxiety respectively. Thus, the outcome in this case appears to be due to rational polypharmcy.

In general, one third patient with a panic disorder remain treatment resistant. Common causes of resistance are comorbid medical, psychiatric disorders (anxiety, mood and substance use disorder) and psychosocial stressors. Augmentation is the most common strategy used to treat such cases. Commonly used augmentation medications with positive results are pindolol, reboxetine, olanzapine, mirtazapine, duloxetine, bupropion, sodium valproate, lithium, levetiracetam, tiagabine, phenelzine, risperidone, quetiapine, and clonazepam. ${ }^{12)}$ Non-pharmacological augmentations reported with positive result are cognitive behavior therapy and repetitive transcranial magnetic stimulation, vagus nerve stimulation. ${ }^{12)}$ As observed in this case, the patient may not respond to different augmenting agents. In such conditions, augmentation is to be individualized rationally (based on pharmacological profiles of medications) depending upon the patient and symptom profile for a successful outcome.

One should be cautious before considering an independent diagnosis of panic disorder in patients with a past history of depression. As per 10th revision of the International Statistical Classification of Diseases and Related Health Problems (ICD 10) if the patient meets the criteria of depression, a diagnosis of panic disorder should not be made. Panic attacks may occur in depression and depression is often accompanied with panic disorder. The lifetime prevalence of major depression in panic disorder is estimated at $50 \%$ to $60 \%$; in about two-thirds of cases, panic disorder precedes the onset of major depression, whereas in one-third major depression precedes the onset of panic disorder. ${ }^{13)}$ Possible explanation is that panic attack may lead to demoralization or distress that increases the risk of depression, or it represents a more severe type of depression or shared etiological factors such as environmental adversities, common trait vulnerabilities such as neuroticism, or shared neurobiological mechanisms, as both conditions respond to the same pharmacological treatments (SSRI). ${ }^{14)}$ In this case, though patient had past episodes of depression, a diagnosis of panic disorder was made as patient did not meet the criteria of depression (mild). With this report, it can be concluded that augmentation of atomoxetine may be useful in treatment resistant panic disorder.

\section{Acknowledgments}

The authors would like to thank Yahosha Kausham, Shamaya Kausham, Hagai Kausham, and Ashther Kausham (Divine Retreat Centre, Chalakudy, Kerla, India) for their moral support.

\section{REFERENCES}

1. Holt RL, Lydiard RB. Management of treatment-resistant panic disorder. Psychiatry (Edgmont) 2007;4:48-59.

2. Kessler RC, Chiu WT, Jin R, Ruscio AM, Shear K, Walters EE. The epidemiology of panic attacks, panic disorder, and agoraphobia in the National Comorbidity Survey Replication. Arch Gen Psychiatry 2006;63:415-424.

3. Zamorski MA, Albucher RC. What to do when SSRIs fail: eight strategies for optimizing treatment of panic disorder. Am Fam Physician 2002;66:1477-1484.

4. Geller D, Donnelly C, Lopez F, Rubin R, Newcorn J, Sutton $\mathrm{V}$, et al. Atomoxetine treatment for pediatric patients with attention-deficit/hyperactivity disorder with comorbid anxiety disorder. J Am Acad Child Adolesc Psychiatry 2007;46:1119-1127.

5. Ravindran LN, Kim DS, Letamendi AM, Stein MB. A randomized controlled trial of atomoxetine in generalized social anxiety disorder. J Clin Psychopharmacol 2009;29: 561-564.

6. Christman AK, Fermo JD, Markowitz JS. Atomoxetine, a novel treatment for attention-deficit-hyperactivity disorder. Pharmacotherapy 2004;24:1020-1036.

7. Charney DS, Heninger GR. Abnormal regulation of noradrenergic function in panic disorders. Effects of clonidine in healthy subjects and patients with agoraphobia and panic disorder. Arch Gen Psychiatry 1986;43:1042-1054.

8. Nesse RM, Cameron OG, Curtis GC, McCann DS, Huber-Smith MJ. Adrenergic function in patients with panic anxiety. Arch Gen Psychiatry 1984;41:771-776.

9. Bymaster FP, Katner JS, Nelson DL, Hemrick-Luecke SK, Threlkeld PG, Heiligenstein JH, et al. Atomoxetine increases extracellular levels of norepinephrine and dopamine in prefrontal cortex of rat: a potential mechanism for efficacy in attention deficit/hyperactivity disorder. Neuropsychopharmacology 2002;27:699-711.

10. Li WY, Strang SE, Brown DR, Smith R, Silcox DL, Li SG, et al. Atomoxetine changes rat's HR response to stress from tachycardia to bradycardia via alterations in autonomic function. Auton Neurosci 2010;154:48-53.

11. Hajós M, Gartside SE, Sharp T. Inhibition of median and dorsal raphe neurones following administration of the selective serotonin reuptake inhibitor paroxetine. Naunyn Schmiedebergs Arch Pharmacol 1995;351:624-629.

12. Menezes GB, Fontenelle LF, Mululo S, Versiani M. Treatment-resistant anxiety disorders: social phobia, generalized anxiety disorder and panic disorder. Rev Bras Psiquiatr 2007;29 Suppl 2:S55-S60.

13. Yates WR. Phenomenology and epidemiology of panic disorder. Ann Clin Psychiatry 2009;21:95-102.

14. Craske MG, Kircanski K, Epstein A, Wittchen HU, Pine DS, Lewis-Fernández R, et al; DSM V Anxiety; OC Spectrum; Posttraumatic and Dissociative Disorder Work Group. Panic disorder: a review of DSM-IV panic disorder and proposals for DSM-V. Depress Anxiety 2010;27:93-112. 